\title{
Funciones de la ideología en la hermenéutica constitucional. Una mirada desde la filosofía de Paul Ricoeur ${ }^{*}$
}

\author{
Andrés Felipe Zuluaga Jaramillo** \\ Santiago de Jesús Zuluaga Vanegas ${ }^{* *}$ \\ Recibido: 4 de diciembre de 2017 - Aprobado: 12 de marzo de 2018 \\ https://doi.org/10.22395/ojum.v17n33a11
}

\begin{abstract}
RESUMEN
El presente texto tiene como fin aclarar el papel de la ideología en la hermenéutica constitucional a partir de la filosofía de Paul Ricoeur. Con base en el filósofo francés se puede comprender que la ideología tiene tres niveles diferentes los cuales llevan a tres funciones, a saber: integración, legitimación y distorsión, las cuales, como se verá, pueden ser llevadas al plano de la interpretación de la Constitución. Para poder mostrar esos usos de la ideología en la hermenéutica constitucional se describirán varios aspectos de la misma, para luego, en un nivel hermenéutico filosófico, proponer la manera en que funciona la ideología en la interpretación de la Constitución.
\end{abstract}

Palabras clave: Ideología; hermenéutica constitucional; Ricoeur; Constitución.

\footnotetext{
El presente artículo es producto del proyecto de investigación en curso llamado Identidad narrativa, lo judicial y casos trágicos: "Las Euménides" de Esquilo. Un acercamiento desde la filosofía de Ricoeur, el cual se encuentra inscrito en el Banco de Proyectos Institucional de la Universidad de Medellín, y se desarrolla en el marco del Doctorado en Filosofía de la Universidad Pontificia Bolivariana (Colombia).

* Abogado de la Universidad de Medellín. Magíster en Derecho Procesal de la Universidad de Medellín (Colombia). Doctorando en Filosofía de la Universidad Pontificia Bolivariana (Colombia). Profesor de tiempo completo, Coordinador de la Unidad de organización curricular de Humanidades de la Facultad de Derecho, miembro del Grupo de Investigaciones Jurídicas de la misma Facultad, de la Universidad de Medellín (Colombia).ORCID: 0000-0002-1601-5325. Correo electrónico: afzuluaga@udem.edu.co

** Egresado no titulado del programa de Derecho de la Facultad de Derecho de la Universidad de Medellín (Colombia). ORCID: 0000-0001-6228-6743. Correo electrónico: santiagozuluaga.v@gmail.com
} 


\section{Functions of Ideology in Constitutional Hermeneutics. A Look from Paul Ricoeur's Philosophy}

\section{ABSTRACT}

This paper aims to clarify the role of ideology in constitutional hermeneutics based on Paul Ricoeur's philosophy. Based on the French philosopher, it can be understood that ideology has three different levels which lead to three functions, namely: integration, legitimation and distortion, which, as will be seen, can be taken to the level of the interpretation of the Constitution. In order to show these uses of ideology in constitutional hermeneutics, various aspects of it will be described, and then, on a philosophical hermeneutical level, the way in which ideology works in the interpretation of the Constitution will be proposed.

Keywords: Ideology; Constitutional hermeneutics; Ricoeur; Constitution; Constitution.

\section{Funções da ideologia na hermenêutica constitucional. Um olhar a partir da filosofia de Paul Ricoeur}

\section{RESUMO}

O presente texto tem como objetivo esclarecer o papel da ideologia na hermenêutica constitucional a partir da filosofia de Paul Ricoeur. Com base no filósofo francês, é possível compreender que a ideologia tem três níveis diferentes que levam a três funções, a saber: integração, legitimação e distorção, as quais, como se verá, podem ser levadas ao plano da interpretação da Constituição. Para poder mostrar esses usos da ideologia na hermenêutica constitucional, serão descritos vários aspectos desta para, posteriormente, em um nível hermenêutico filosófico, propor a maneira em que a ideologia na interpretação da Constituição funciona.

Palavras-chave: Constituição; hermenêutica constitucional; ideologia; Ricoeur. 


\section{INTRODUCCIÓN}

El propósito de este artículo es diferenciar cuál es el papel de la ideología en la hermenéutica de la Constitución. El punto de partida es que la ideología no funciona de una sola manera al momento de determinar el sentido de las disposiciones normativas de la Constitución; esto, porque el concepto de ideología no remite a un único significado. Para poder realizar la distinción que se pretende el texto se divide en dos partes: la primera de ellas aborda el tema de la interpretación constitucional con el propósito de mostrar qué se entiende por hermenéutica constitucional, cuáles son los fenómenos que llevan a interpretar la Constitución, quiénes están llamados a interpretarla, las posturas originalista y del constitucionalismo viviente, y por último los temores frente a la hermenéutica constitucional.

En la segunda parte, se aborda el concepto de ideología desde la óptica del filósofo francés Paul Ricoeur para aclarar los tres niveles de la ideología, y a partir de allí mostrar cómo se relacionan con la interpretación constitucional. De este modo, se aclarará que la presencia de la ideología al momento de interpretar la Constitución no es ni buena ni mala por sí misma; más bien se mostrará que esta puede funcionar de tres maneras distintas, (i) integrando (ii) legitimando, o (iii) distorsionando. Diferenciar cada uno de esos tres usos en las interpretaciones constitucionales realizadas en casos concretos es la clave para saber cuál fue el uso de la misma y si este se compadece con lo que debe ser la interpretación constitucional en un Estado constitucional y democrático de derecho.

La metodología utilizada para la realización de este artículo es la hermenéutica filosófica de Paul Ricoeur. La hermenéutica filosófica del autor francés, entre otros aspectos, establece que "el decir del hermeneuta es un re-decir, que reactiva el decir del texto" (Ricoeur, 2004, p. 147). En otras palabras, la hermenéutica filosófica de Ricoeur invita a indagar en el texto para encontrar significados que no están expresamente allí, los cuales permiten actualizar la obra.

Además, la hermenéutica filosófica del filósofo francés tiene en cuenta que "el problema hermenéutico se plantea ante todo dentro de los límites de la exégesis, es decir, en el marco de una disciplina que se propone comprender un texto, comprenderlo a partir de su intención" (Ricoeur, 2008a, p. 9), lo cual invita a ponerse en el sentido del texto, pero no para repetirlo; sino para salvar la distancia frente al texto, apropiárselo, re significarlo, lo cual permite comprenderse mejor, comprender mejor al otro y a las instituciones.

Con base en lo anterior se abordarán los textos en los cuales Ricoeur aborda el tema de la ideología y especialmente la obra "Ideología y utopía", es decir, se busca reactivar sus significados a luz de la hermenéutica constitucional, para comprender mejor cómo funciona la ideología en la interpretación de la Constitución. 


\section{CONSTITUCIÓN Y HERMENÉUTICA JURIDICA}

En esta primera parte se realizará un acercamiento al concepto de Constitución para establecer un lenguaje común con el lector, para luego abordar la interpretación constitucional y por último se señalarán algunos temores frente a la interpretación de la Constitución, siendo el más importante el de la ideología.

\section{Aproximación a un concepto de Constitución}

La Constitución puede ser conceptualizada desde varios puntos de vista; para efectos de este artículo, se acudirá a dos posturas representativas las cuales describen la Constitución desde perspectivas diversas, a saber (i) la normativista y (ii) la sociológica.

i) Teoría normativista. La Constitución política puede ser vista como un producto normativo con funciones meramente jurídicas ligadas a la validez de las demás normas del ordenamiento jurídico. De este modo, la Constitución desempeña un papel crucial ya que "Se crea así una cadena en la cual la validez de las normas que la componen deriva de la norma jerárquica superior, según vamos ascendiendo en la pirámide, hasta llegar a la Constitución, que es la norma jurídica positiva de jerarquía más alta" (Robles, 2012, p. 257). Por lo anterior, se podría afirmar que para quienes sostienen dicha postura la función de la Constitución política es meramente irradiadora de validez para las demás normas de inferior rango que conforman el ordenamiento jurídico.

ii) Teoría sociológica. Esta teoría también es denominada como constitucionalismo viviente. Acá se cuestiona si la función normativa es la única función de la Constitución. Para esta postura no basta con ver la Constitución como una simple "acción referida a una especie de ley y ésta, como todo cuerpo normativo, ordena, prohíbe o permite" (Arteaga, 2005, p. 62). Para esta teoría enfocar la Constitución como un mero producto normativo es desacertado, ya que también puede ser vista como aquel texto integrador de todo un pueblo a través de su historia; en este sentido Háberle ha expresado que "La Constitución no es solo un texto jurídico o un código normativo, sino también la expresión de un nivel de desarrollo Cultural, instrumento de representación cultural autónoma de un pueblo, reflejo de su herencia cultural y fundamento de nuevas esperanzas" (Háberle, 2002, p. 72).

Con base en lo anterior, se puede establecer que la Constitución puede ser vista como un mecanismo de auto representación de la identidad de una nación, puesto que todos los pueblos a través de su historia van forjando una identidad la cual se refleja en el texto constitucional. Esta identidad se construye con base en una memoria colectiva, pues las costumbres, creencias, luchas y acontecimientos más relevantes sirven de base para la construcción del imaginario social y como mecanismo de 
integración de cada comunidad. Es así como la Constitución política debería ser el reflejo de los pilares fundacionales de cada pueblo y un instrumento integrador y legitimador de cada comunidad; en últimas, debería ser aquella "estructura simbólica de la memoria social" (Ricoeur, 2004, p. 354).

A partir de las dos posturas mencionadas cabe preguntarse: ¿Cuál es entonces la función de la Constitución? Ambas teorías se basan en puntos cruciales que no pueden ser desconocidos; no se trata de escoger entre blanco y negro, sino de buscar el punto de compatibilidad entre las dos posturas; no se puede desconocer que la Constitución es la norma suprema que irradia de validez todo el ordenamiento jurídico ni que la Constitución emana del constituyente primario que es el pueblo y es ahí donde el texto constitucional debe ser visto como un mecanismo de integración el cual sirve como medio de auto representación y como reflejo de la herencia cultural de cada comunidad. En suma, la Constitución es un texto viviente, integrador, plagado de sentidos extrajurídicos que tiene carácter de normar jurídica suprema y delimitadora del ordenamiento jurídico.

\subsection{Hermenéutica constitucional}

Para abordar el tema de la interpretación constitucional primero se delimitará qué

Sobre el tema puede consultarse Bocanument, Restrepo y Rojas (2015) los cuales abordan los Tipos y modalidades de participación en el proceso político constituyente de 1990-1991 en el Estado de Colombia. se entenderá por hermenéutica en este artículo. Es de recordar que el sentido clásico de la expresión hermenéutica es el "arte de interpretar textos" (Grondin, 2008, p. 16), por lo cual, como lo expresa Grondin (2008), su función era meramente auxiliar, es decir, se acudía a la hermenéutica cuando el intérprete "se enfrentaba a pasajes ambiguos (ambigua) o chocantes" (p. 17); por ello la hermenéutica clásica era principalmente normativa, pues proponía reglas o cánones para la interpretación. Es de anotar que el filósofo canadiense que se comenta menciona que la teología, la filología y el derecho han utilizado la hermenéutica en un sentido clásico (Grondin, 2008, p. 16).

Con base en lo anterior, no sorprende que autores, como Savigny, hayan hablado de cánones de interpretación, los cuales remiten directamente a la función normativa de la hermenéutica clásica; como se sabe, para este autor "los primordiales métodos interpretativos son el gramatical, el lógico, el sistemático e histórico" (Burgoa, 2005, p. 229), los cuales permiten determinar el significado de aquellos pasajes oscuros o ambiguos. Según Asís Roig (2008), "Todos los ordenamientos jurídicos cuentan con criterios de este tipo cuya tradición se remonta a los propios orígenes de la idea del derecho" (p. 213). Es de anotar que en el caso del ordenamiento jurídico colombiano se verifica la tesis mencionada, pues el artículo 27 del Código Civil preceptúa que: "Cuando el sentido de la ley sea claro, no se desatenderá su tenor literal a pretexto de consultar su espíritu. Pero bien se puede, para interpretar una 
expresión oscura de la ley, recurrir a su intención o espíritu".

De este artículo se desprende cómo la hermenéutica jurídica es algo meramente auxiliar, que su uso se da ante pasajes ambiguos y se imponen reglas para realizar la interpretación. Ahora bien, en la actualidad el concepto de interpretación jurídica se ha desligado de esa función meramente auxiliar, aunque guarda ciertos rasgos como los preceptos interpretativos.

Es de anotar que la palabra hermenéutica también puede remitir a un significado diferente del clásico ya que puede ser vista como una rama de la filosofía (hermenéutica filosófica) que busca, a través de reflexiones metodológicas, la pretensión de verdad o partir de reflexiones que lleven a una filosofía de la existencia como lo planteaba Heidegger; así, "la hermenéutica en principio nada tiene que ver con los textos, sino con la existencia misma" (Grondin, 2008, p. 19). Para esta forma de pensar la filosofía, es la existencia misma del hombre la que se vuelve hermenéutica.

Aclaradas esas formas de verla se delimitará el sentido del término "interpretación" a una esfera netamente jurídica. Por lo anterior, se partirá de dos definiciones que se contraponen y al mismo tiempo se complementan según la primera: "Interpretar denota una operación intelectual consistente en determinar el alcance, extensión, el sentido o el significado de cualquier norma jurídica" (Burgoa, 2005, p. 227). Esta definición del profesor Burgoa
Orihuela se restringe a un concepto de interpretación denominado por Guastini como juez fiel a la ley; la segunda definición establece que "la interpretación se presenta no como "averiguación", sino como valoración, elección, y decisión" (Guastini, 1997, p. 121). Para esta forma de definir la interpretación la misma no se reduce a una mera operación intelectual y normativa encaminada a determinar el significado de algún pasaje oscuro, sino que incluye elementos valorativos.

Por la importancia que tiene para este artículo la manera en que funciona la hermenéutica se cita in extenso a Guastini para quien las funciones de la interpretación se pueden configurar de dos modos diversos:

Desde el punto de vista del juez fiel a la ley, la interpretación se presenta como una actividad de conocimiento: interpretar es "averiguar" el "verdadero" significado de las leyes y/o la "verdadera" intención del legislador. Los problemas de interpretación, a su vez, se presentan como fuentes o motivos de duda en torno al significado de la ley o a la intención del legislador. Desde el punto de vista del "hombre malo" -O, más sencillamente, del abogado o, incluso, del juez ligado no a la ley sino a su propia orientación políticala interpretación se presenta no como "averiguación", sino como valoración, elección, y decisión: interpretar es individualizar los diversos posibles significados de un texto, valorar cada uno los posibles resultados prácticos, y escoger el más oportuno en vista a un fin preestablecido. (Guastini, 1997, p. 121) 
Es de resaltar la expresión de un juez ligado "a su propia orientación política" el cual valora y escoge algún significado con base en esa orientación política, esto muestra la presencia tácita de la ideología al momento de definir la interpretación.

A modo de síntesis, se propone entender como hermenéutica jurídica una actividad intelectual encaminada a determinar el sentido y alcance de los textos jurídicos en un plano de valoración, elección y decisión.

Es de anotar que entre la hermenéutica jurídica en general y la constitucional la diferencia no es cualitativa; la diferencia se encuentra en cuanto al objeto de la interpretación, y la importancia del mismo. El objeto de la interpretación constitucional es la Constitución, y este es punto de partida para determinar el significado de todo el ordenamiento jurídico; no en vano se ha expresado que

La Constitución crea y determina el sistema jurídico; de su carácter supremo se sigue que es el sistema de significaciones jurídicas del cual se derivan los significados de las demás normas del sistema. En virtud de su posición dentro de un esquema de organización jerárquico predomina sobre el resto del orden jurídico, y por lo mismo se configura como su elemento fundamental de interpretación. Es el marco interpretativo de referencia. (Huerta, 2008, p. 313)

\subsubsection{Fenómenos que llevan a interpretar la Constitución}

Básicamente hay dos fenómenos que llevan a interpretar la Constitución: (i) el lingüístico, donde la textura abierta del lenguaje juega un papel preponderante, y es el intérprete quien debe determinar el sentido del texto constitucional, y (ii) el cultural el cual sitúa la interpretación de la Constitución en el complejo proceso evolutivo de las sociedades.

\section{COMO FENÓMENO LINGÜÍSTICO}

Una de las razones que llevan al porqué de la interpretación radica en el papel jugado por el lenguaje. El lenguaje usado en la cotidianidad suele ser llamado natural, el cual no siempre exige unos usos técnicos; el derecho se construye con base en ese lenguaje natural y se separa gradualmente de este al establecer un lenguaje técnico. El lenguaje técnico jurídico aspira a ser claro y coherente en aras de garantizar una mayor confianza en el momento de la aplicación de las disposiciones normativas; ahora bien esto no significa que este tipo de lenguaje tecnificado sea esquivo a problemas semánticos, sintácticos y pragmáticos. Son problemas lingüísticos la ambigüedad ${ }^{2}$ y la vaguedad ${ }^{3}$.

\footnotetext{
La ambigüedad debe ser estudiada en sus tres acepciones: 1) La ambigüedad semántica, 2) La ambigüedad sintáctica 3.) La ambigüedad Pragmática (Guastini, 1997).

3 "La vaguedad es, entonces una propiedad de la referencia de los predicados. Un predicado es vago siempre que la pregunta "¿A qué cosa se refiere?" admita una respuesta dudosa" (Guastini, 1997, p. 124).
} 
Ahora bien, la particularidad del texto constitucional es que utiliza términos del lenguaje natural y del técnico jurídico, los cuales adolecen de problemas de textura abierta, sumándose que al estar presentes en la Constitución adquieren una fuerte carga axiológica, política, emotiva e ideológica, por lo cual el determinar el sentido de palabras como 'vida', presentes en el texto constitucional, parte del fenómeno lingüístico, pero lo desborda.

\section{COMO FENÓMENO CULTURAL}

Partir de la idea de que la Constitución de cada pueblo no evoluciona con sus generaciones significaría decir que dicho texto es estático en el tiempo, convirtiéndose así (metafóricamente hablando) en letras muertas, que no estarían acordes con los cambios sociales, lo cual podría generar una disociación entre la realidad social y lo plasmado en el texto constitucional; por este motivo es necesario preguntarse "hasta qué punto resulta indispensable una interpretación constitucional evolutiva, que permita dotar al texto de un sentido de realidad y de contemporaneidad que logre evitar su natural desgaste" (Carbonell, 2012, p. 349).

Los cambios culturales en una sociedad invitan a actualizar el sentido de las disposiciones constitucionales a través de la interpretación constitucional para que la misma sea acorde con la realidad social de cada generación; esto no significa abandonar las raíces que dieron origen a la Constitución de cada pueblo, sino que es más bien un mecanismo por el cual el texto político se va acoplando a las realidades sociales y culturales de cada comunidad.

Lo anterior resulta de vital importancia para aquellas palabras cargadas de contenido ideológico, pues es menester que el intérprete constitucional reconozca la diversidad cultural de cada generación; es por esto que Strauss, (como se citó en Carbonell, 2012, p. 349) establece: "Una constitución viviente, es una constitución que evoluciona, que cambia con el paso del tiempo y que se adapta a las nuevas circunstancias, pese a que no es formalmente modificada mediante el proceso constitucional".

\subsection{2. ¿Quiénes están llamados a interpretar la Constitución?}

Hablar acerca de quién está legitimado para realizar el acto interpretativo de la Constitución conduce inmediatamente adoptar dos sentidos, uno amplio y uno restrictivo:

(i) En sentido amplio la interpretación constitucional no debe estar en cabeza de unos pocos sino de todos los individuos y órganos que conforman el Estado. Háberle ha expresado que "en los procesos relacionados con la interpretación constitucional toman parte potencialmente todos los órganos estatales, todos los ciudadanos y todos los grupos. iNo existe ningún numero clausus de los intérpretes constitucionales!" (Haberle, 2002, p. 112). En otras palabras, todos los sujetos son intérpretes directos o 
indirectos de la Constitución, pues la misma va más allá de ser un mero fenómeno jurídico y se inserta en la realidad de una determinada comunidad, tornándose la Constitución en algo vivo en medio de las sociedades abiertas.

(ii) En sentido restringido, se establece que el intérprete legítimo de la Constitución debe ser un órgano del Estado, a saber el Tribunal Constitucional; para esta posición "La tarea del Tribunal constitucional incluye resolver conflictos de carácter constitucional, como la revisión de la actuación del poder Legislativo, la protección de los derechos fundamentales y la distribución de competencias entre los poderes constituidos" (Higton, 2010, p. 108). Es de anotar que en los Estados en los cuales existe el control difuso ${ }^{4}$ o mixto, la interpretación de la Constitución recae sobre varios órganos competentes para realizarla. Se ha expresado que en el sistema difuso

\footnotetext{
Los dos modelos institucionales primarios del derecho occidental presentan diferencias sustanciales en cuanto al órgano en cargado de ejercer el control de constitucionalidad. A) Por un lado está el esquema de revisión judicial o judicial review, por el cual se deja en manos de los jueces que integran el Poder Judicial la tarea de interpretar y aplicar la ley en el caso concreto, respetando en sus sentencias el principio de la supremacía constitucional. Este sistema denominado difuso confiere a todos los jueces la tarea de control. O sea que todos los jueces son jueces de legalidad y de constitucionalidad. B) Por otro lado, se presenta el sistema concentrado del modelo europeo que centraliza el ejercicio del control constitucional en un único órgano, que no forma parte del Poder Judicial, está fuera de su estructura normativa y se denomina Tribunal Constitucional (Higton, 2010).
}

[... el juez tiene el deber de realizar una interpretación para llegar a un juicio con respecto a la constitucionalidad de la norma. La decisión del juez ordinario es tan legítima como la decisión de supremo Tribunal, ya que tanto el juez ordinario como el supremo Tribunal, tiene legitimidad constitucional para tratar de la cuestión de constitucionalidad. (Higton, 2010, p. 111)

Desde el punto de vista de intérpretes constitucionales restringidos, el problema de las interpretaciones abiertas radica esencialmente en la legitimidad que tienen los sujetos, pues desde la perspectiva jurídica estas interpretaciones de la Constitución no tienen fuerza vinculante, por lo cual no obligan a las autoridades públicas ni a los particulares.

\subsubsection{Posturas frente a la interpretación constitucional: originalista 0 constitucionalismo viviente}

La interpretación constitucional puede verse desde dos grandes frentes: la postura originalista o la del constitucionalismo viviente, bandos que tienen origen en el derecho anglosajón, y específicamente en las altas cortes norteamericanas. El inicio de este debate surge por la problemática que tienen los textos constitucionales de adecuarse a la realidad social de cada generación, y el asunto es aún más complejo cuando el medio de reforma constitucional no termina siendo muchas veces el adecuado para mantener al texto Constitucional acorde con la realidad social. 
i) Judicial restrain o postura originalista. Los defensores de esta postura aducen "Que una constitución pueda sufrir cambios por vías interpretativas, sin ser formalmente enmendada, genera enormes riesgos. La constitución viviente, dicen quienes discrepan, permiten que su texto sea manipulable" (Carbonell, 2012, p. 350). Los partidarios de esta postura proponen que la interpretación constitucional sea de carácter restrictivo. Para Guastini (2010) esta postura "favorece entonces la interpretación literal y/u originalista y/o conservadora" (p. 64), puesto que pretenden que la interpretación constitucional se enmarque en alguna de estas tres hipótesis: (i) respeto del sentido literal del texto constitucional (plain meaning); (ii) respeto de la intención original del constituyente (the original intent) $\mathrm{O}$ (iii) respeto de los precedentes consolidados.

La postura originalista pretende evitar la manipulación del texto constitucional por parte de los intérpretes constitucionales, lo cual supone mantener la ideología de otra época en la sociedad actual, y evita que otras ideologías cambien el significado del texto constitucional, como si los individuos y las sociedades debieran acomodarse a la ideología de la Constitución.

\section{ii) Activismo judicial o constitucio-} nalismo viviente. Esta doctrina encuentra sus bases en la armonía que debe existir entre las normas del texto constitucional y la realidad social; es por esto que se plantea una interpre- tación evolutiva, la cual pueda dotar a la Constitución de nuevos significados acordes con la realidad a la cual se encuentra dirigida. Para los defensores del constitucionalismo viviente el texto constitucional debe responder a las necesidades de la sociedad a la cual se dirige. Guastini (2010) aduce que este bando "favorece la "libre creación" del derecho constitucional por parte de los jueces, con la finalidad de adaptar los valores constitucionales a las necesidades de la vida real, que los jueces solo pueden identificar mediante sus sentimientos de justicia" (p. 65). Las consecuencias de esta postura son tres: (i) se abandona el sentido literal, (ii) se favorece la interpretación evolutiva, y (iii) posibilita la construcción de normas jurídicas implícitas.

De allí se desprende que ellos depositan una alta confianza en los jueces, porque en ellos recae la ardua tarea de materializar el sentimiento de justicia 5 . Acá es la Constitución la que debe moldearse a los cambios sociales, lo cual puede suponer interpretar la Constitución con base en una ideología que no era la originaria, pero que lentamente va modificando el sentido del texto constitucional.

\footnotetext{
La justicia es la primera virtud de las instituciones sociales, como la verdad lo es de los sistemas de pensamiento. Una teoría, por muy atractiva, elocuente y concisa que sea, tiene que ser rechazada o revisada si no es verdadera; de igual modo, no importa que las leyes e instituciones estén ordenadas y sean eficientes: si son injustas han de ser reformadas o abolidas. Puede verse en Rawls (1995).
} 


\subsubsection{Temores frente la interpretación constitucional} La adaptación de la Constitución política a la realidad social trae consigo ciertos temores los cuales hacen que la adecuación por vías interpretativas del texto constitucional sea vista con recelo; en este apartado se esbozará el temor más arraigado que hay en este tema el cual radica en que el carácter dogmático e ideológico del intérprete legítimo pueda afectar la fijación de sentido de la Constitución.

La ideología es vista como un temor constante ${ }^{6}$ ya que es considerada como aquel mecanismo que trata de deformar o distorsionar una imagen clara que se tiene sobre algún concepto. Es por esto que la ideología es vista desde una categoría de distorsión y disimulo, que solo sirve para legitimar o imponer una forma de poder, y cuando se habla de interpretación, y más del texto constitucional, este temor se hace más fuerte.

No se puede negar que el intérprete a la hora de enfrentarse con el texto normativo trae consigo una serie de dogmas, que su mismo grupo social le ha forjado; por esto su interpretación puede estar condicionada ya que "Toda construcción dogmática condiciona la interpretación, bien sea sugiriendo una decisión interpretativa determinada que se prefiere sobre las demás, bien excluyendo ciertas decisiones interpretativas

6 La ideología es entonces asimilada pura y simplemente a un engaño social o, lo que es más grave, a una ilusión protectora de nuestro estatus social, con todos los privilegios y las injusticias que esto incluye. Puede verse en: Ricoeur (2004). de otras formas posibles" (Guastini, 2008, p. 33). Por este motivo los escépticos de la interpretación constitucional cuestionan la preponderancia del intérprete, ya que argumentan que el aumento de discrecionalidad judicial puede ser desbordado lo cual podría generar que el juez sea quien a partir de sus interpretaciones distorsione o deforme el texto constitucional y sea quien legitime a un grupo (con tintes autoritarios) en ascenso y pueda deslegitimar y atacar al poder legítimamente constituido.

Así bien, se podría entonces decir que el término ideología parece que hiciera referencia, no a sistemas de creencias, sino a asuntos relativos al poder, como lo argumenta Terry Eagleton. Parece que este término solo se pudiese ver como aquel fenómeno que legitima a un grupo o clase social dominante; es así como al estudiar el concepto de ideología, John B. Thompson (como se citó en Terry Eagleton, 1997), aduce: "[...] estudiar las formas en que el significado (o la significación) sirve para sustentar relaciones de dominio"; es ahí donde se puede observar cómo gira el temor de la interpretación constitucional a un efecto de legitimación del poder.

Siguiendo con la línea anterior Eagleton muestra cómo este temor ideológicolegitimador se va edificando en seis peldaños:

Un poder dominante se puede legitimar por sí mismo promocionando creencias y valores afines a él; naturalizando y universalizando tales creencias para hacerlas evidentes y aparente- 
mente inevitables; denigrando ideas que puedan desafiarlo; excluyendo formas contrarias de pensamiento, quizá por una lógica tácita pero sistemática; y oscureciendo la realidad social de modo conveniente así misma. (Eagleton, 1997, p. 24)

Los escépticos de la interpretación constitucional podrían encontrar gran fuerza en estos seis pilares ya que, como se ha visto, podría ser el juez un sujeto condicionado por unos dogmas prestablecidos que lo llevasen a tratar de deformar el texto constitucional a través de sus interpretaciones.

Pero antes de tomar una postura frente a este temor, es necesario abordar los tres niveles de la ideología plateados por el filósofo Paul Ricoeur y de este modo esclarecer cómo funciona la ideología al momento de la interpretación constitucional.

\section{LA IDEOLOGÍA EN PAUL RICOEUR}

El filósofo francés se ha ocupado varias veces del concepto de ideología. Acá se recuperarán algunas de sus reflexiones para extraer algunas consecuencias para la hermenéutica constitucional. El punto de partida de este texto es que no se puede simplemente oponer hermenéutica filosófica y crítica de las ideologías. Ricoeur expresa: "la crítica de las ideologías es el rodeo necesario que debe hacer la autocomprensión, para que pueda formarse por la cosa del texto y no por los prejuicios del lector" (2004, p.
110). Así como Ricoeur no oponía estos dos aspectos se mostrará cómo pueden conciliarse la hermenéutica constitucional y el uso de la ideología en la misma; con esto se podrá comprender mejor lo que acontece cuando se interpreta la Constitución por parte de los tribunales constitucionales.

En este apartado se responderá a la pregunta: ¿Cuál es la función de la ideología en la hermenéutica constitucional con base en Ricoeur? Para hacerlo se debe aclarar que el concepto de ideología en Ricoeur no es unívoco, más bien es un concepto que se eslabona en tres niveles los cuales, a su vez, indican tres formas de uso de la ideología; a partir de esos tres niveles se mostrará su presencia en la interpretación de la Constitución.

\subsection{Nivel l: integración}

Según Ricoeur "el fenómeno ideológico... está ligado a la necesidad que tiene un grupo social de darse una imagen de sí mismo, de representarse, en el sentido teatral de la palabra, de ponerse en juego y en escena" (2004, p. 282). De esta cita debe hacerse énfasis en la necesidad; la ideología según esto no es un aspecto accesorio o contingente en los grupos sociales; la ideología funciona entonces movilizando, justificando, motivando acciones y proyectando la acción de un determinado grupo social. En otras palabras, en este nivel la ideología permite integrar, cohesionar, construir vínculos en un determinado grupo social, genera identidad, consistencia y permanencia, en últimas, genera una imagen estable y 
perdurable del grupo social, y "esta imagen estable y perdurable expresa el nivel más profundo del fenómeno ideológico" (Ricoeur, 2004, p. 355).

Ese carácter dinámico de la ideología como integración viene reforzado por su carácter codificado, es decir, simplifica y esquematiza una serie de ideas que se convierten en el patrimonio común de los miembros del grupo, y al ser así establecen un marco dóxico para la interpretación de sí mismo, del otro y del mundo. Así el "código interpretativo de una ideología es algo en lo cual los hombres habitan y piensan, más que una concepción que ellos ponen ante sí" (Ricoeur, 2004, p. 284); la ideología como integración se torna operatoria en la medida que moviliza significados y sentidos en el grupo social, y hace que los sujetos hagan ciertas interpretaciones del mundo que los mantienen ligados al grupo social. Desde la ideología del grupo social se ve el mundo, se habita y se piensa; esto ratifica el carácter necesario de la ideología.

Es de precisar que en este primer nivel la ideología no tiene aún una connotación peyorativa, es un aspecto indispensable para cualquier grupo social, una imagen de sí a través de la cual se interpreta el mundo. A partir de esto se puede retornar al plano jurídico para afirmar que la Constitución política tiene un carácter ideológico, ya que si "la política es el terreno en que las imágenes básicas de un grupo suministran en definitiva reglas para ejercer el poder" (Ricoeur, 2008b, p. 280), la Constitución es el texto en el cual ese terreno adquiere un lugar delimitado, y reposan esas imágenes del grupo social. En este punto la Constitución en los Estados sociales y democráticos de derecho funciona ideológicamente para integrar a un pueblo. En otras palabras, en la Constitución reposa parte del imaginario social, la manera en que una sociedad se ve a sí misma y también de la imagen que se aspira a tener, imagen en cuanto muestra lo que es (como un retrato), pero también en cuanto proyecta algo que aún no se es, que está ausente. Así la Constitución es la imagen de aquello que está presente y es la evocación de lo ausente en la sociedad, pero es una ausencia que busca ser presencia para así continuar integrando el grupo social.

¿La interpretación de la Constitución puede ser ajena a la ideología como integración? Se estima que no, porque el texto constitucional es producto de una ideología en su nivel de integración la cual responde a la imagen que de sí tiene el grupo social. Ahora bien, si el texto constitucional es producto de una imagen y su interpretación es realizada por un Tribunal Constitucional cuyos miembros fueron modelados por ese grupo social que, se reitera, le dio un código interpretativo, entonces en este primer nivel la ideología es usada en la interpretación constitucional, y si esta manera de la ideología no es peyorativa, entonces la presencia de la misma en la interpretación constitucional tampoco lo es. Ross expresa que "el juez no es un mero fenómeno biológico sino también un fenómeno cultural" (1977, p. 96) y como tal las decisiones que debe 
tomar se encuentran permeadas por "presuposiciones tácitas en la forma de credo y prejuicios, aspiraciones, standards y valoraciones, que existen en la tradición de cultura que rodea por igual al legislador y al juez." (1977, p. 96). Todo esto indica que la ideología, y su correlativo reflejo en la Constitución va formando un sentido de justicia el cual es tenido en cuenta de manera implícita al momento de atribuir significado a las diversas disposiciones normativas del texto constitucional.

Es de anotar que en el plano de las directivas de interpretación constitucional se ha propuesto el criterio de eficacia integradora el cual busca conservar la integración del Estado o la unidad política; así se "exige otorgar preferencia en la solución de los problemas jurídicoconstitucionales a aquellos puntos de vista que promuevan y mantengan dicha unidad" (Hesse, 2011, p. 69). En los términos utilizados en este artículo, esto viene a decir que al momento de interpretar la Constitución debe intentar preservarse la imagen proyectada en la Constitución para mantener la integración del grupo; en otras palabras, se busca mantener el vínculo social generado por la Constitución a través de la interpretación de la misma.

Otro aspecto a resaltar en la ideología como integración es lo que se ha llamado sentimiento constitucional, Loewenstein (1982) expresa que este

[...] se podría describir como aquella conciencia de la comunidad que, trascendiendo a todos los antagonismos y tensiones existentes político-partidistas, económico-sociales, religiosos o de otro tipo, integra a detentadores y destinatarios del poder en el marco de un orden jurídico obligatorio, justamente la Constitución, sometiendo el proceso político a los intereses de la comunidad. (p. 200)

Se relievan las expresiones 'conciencia de la comunidad' e 'integra a detentadores y destinatarios'; estas dos ideas verifican como la Constitución va más allá de ser un mero texto normativo, y cómo en él confluye una ideología que permite ir más allá de contradicciones sociales e integrar a la comunidad en torno a unos mínimos supuestos ideológicos que se tornan en lazo de unión en el cual los hombres habitan. Loewenstein expresa que ese sentimiento constitucional se puede reforzar por medio de la educación y el buen manejo del simbolismo nacional; así la Constitución y sus supuestos ideológicos se van inculcando en las nuevas generaciones logrando mantener integrada a la comunidad en torno a una ideología reflejada en el texto constitucional.

Por ello no sorprende que algunos autores expresen que para interpretar la Constitución debe haber una "sensibilidad del juez constitucional" (Carmona, 2005, p. 294), sensibilidad hacia los diversos aspectos fundamentales de la Constitución los cuales obviamente involucran aspectos ideológicos. En este sentido también se ha dicho que se requiere "una particular 'sensibilidad', que le permita captar la 
esencia, penetrar en la entraña misma y comprender la orientación de las disposiciones fundamentales" (Carpizo y FixZamudio, 2005, p. 398) ${ }^{7}$, orientación que viene delineada por un fondo ideológico que integra la comunidad y que deber ser respetado y mantenido por el intérprete constitucional.

\subsection{Nivel 2: legitimación}

En todo grupo social se generan relaciones de poder, y algunos de los actores pretenden erigirse en autoridad frente a otros, dominar a otros, pero los miembros de un grupo obedecen a aquella autoridad que se torna legítima, y es en la legitimidad donde se encuentra de nuevo a la ideología, porque "Allí donde hay una reivindicación de legitimidad, se recurre a la retórica del discurso público con una finalidad de persuasión" (Ricoeur, 2004 , p. 353). La ideología entonces genera la creencia en la legitimidad de aquel o aquellos que ejercen el poder; la ideología persuade de que esto debe ser así; la ideología le presta una voz a la autoridad para que ella cree la imagen de su legitimidad.

Ricoeur expresa que "la fuerza bruta no triunfa sin un ejercicio de persuasión confiado a sofistas públicos" (Ricoeur, 2004, p. 352). Estos, con base en la ideología, refuerzan las normas y el simbolismo

$7 \quad$ En este mismo sentido se ha dicho que "Ha determinado la necesidad de que los jueces constitucionales estén dotados de una sensibilidad política y social que les permita descubrir en las disposiciones fundamentales, los principios y valores de una comunidad política en un momento determinado" (Fix-Zamudio, 2005, p. 564). social, y generan todo un marco interpretativo frente a unas determinadas formas de ejercicio del poder, haciendo ver que estas son las legítimas. Uno puede no haber leído el Contrato social, de Rousseau, pero conoce la expresión, y la ha oído usar infinidad de veces en la justificación de la democracia.

El filósofo francés admite el poder simbólico de "un texto, el de un enunciado, para ser persuasivo, engendrar la creencia" (Ricoeur, 2008c, p. 90). Para el tema objeto de estudio la Constitución es un texto con un alto grado de poder simbólico el cual produce la creencia de que aquellos que ejercen el poder con base en las normas allí establecidas son autoridades legítimas. En las sociedades occidentales la legitimación se engendra desde la Constitución y sus procedimientos democráticos. Siguiendo a Weber en este punto en las sociedades en las cuales el texto constitucional es fuente de legitimidad estamos en presencia de una legitimidad "de carácter racional: que descansa en la creencia en la legalidad de ordenaciones estatuidas y de los derechos de mando de los llamados por esas ordenaciones a ejercer la autoridad" (2005, p. 172).

En este orden de ideas, la ideología se encuentra presente en la Constitución ya que la misma es producto de unas fuerzas políticas que dan lugar a ella, y que se legitiman a través de la Constitución la cual refleja la ideología de ese poder político; así "aun aquellos regímenes políticos que se basan en el simple hecho de la fuerza se sienten obligados a colgar de sus bayonetas una bandera ideológica" 
(Loewenstein, 1982, p. 32), con la cual buscan revestirse de legitimación. No en vano se encuentra en la Constitución una serie de normas acerca de la manera de elección de las personas que integran los órganos del poder público.

Aceptar la presencia de la ideología en su segunda función en la Constitución lleva necesariamente a establecer que la interpretación constitucional también hace uso de la misma, ya que lo que le sucede al objeto de interpretación permea la actividad de interpretar; esto nos permite comprender que la función de los tribunales de salvaguardar la Constitución es proteger una determinada forma de legitimación del poder político; por ello la interpretación de la Constitución está condicionada a respetar y reforzar esa legitimidad.

En lo que Loewenstein llama límites inmanentes a la reforma constitucional se encuentra una manifestación de la ideología en su función legitimadora; estos límites a la reforma "se producen por la inmunidad de que gozan ciertos valores ideológicos fundamentales, implícitos, inmanentes o inherentes a una Constitución" (1982, p. 192), y esta inmunidad debe ser controlada por los tribunales constitucionales evitando reformas constitucionales que vayan en contravía de las cláusulas intangibles. De este modo, la interpretación de la Constitución conlleva atribuirle significado a esos valores ideológicos fundamentales para luego hacer un contraste con la reforma y determinar la compatibilidad o no de la misma con esos aspectos inherentes a la Constitución. Esos valores ideológicos fundamentales son la base de la legitimación del sistema jurídico político y, por ende, deben ser defendidos a través de una interpretación constitucional que parta de la ideología en su segunda función.

\subsection{Nivel 3: la ideología como distorsión o disimulo}

Ricoeur expresa que esta función de distorsión, disimulo o deformación por inversión de la ideología es la conceptualizada por Marx. Como se sabe la ideología vista desde esta perspectiva es aquella que se torna como función negativa y es objeto de crítica. Como lo expresa el filósofo francés las dos funciones anteriores de la ideología son positivas, y esta última es la manifestación patológica.

¿Qué es aquello que deviene deformado por inversión? Es la realidad; la ideología hace ver únicamente la imagen, desarraigándola de la vida. De este modo, "La ideología constituye el procedimiento general mediante el cual el proceso de la vida real, la praxis, es falsificado por la representación imaginaria que los hombres se hacen de él" (Ricoeur, 2004, p. 351). La ideología vista desde esta tercera función lleva la imagen hacia el exceso; de una ideología que cohesionaba un grupo social y legitimaba una forma de poder, se pasa a una en la cual prevalece la imagen por la imagen misma, y esto hace que la vida real sea mirada con una imagen falsa o, en otras palabras, no es la realidad la que genera las imágenes: es la ideología distorsionadora la base para aproximarse a la realidad. 
En este sentido puede citarse a Debord quien expresa que en la sociedad del espectáculo "los hechos ideológicos nunca han sido simples quimeras, sino una conciencia deformada de las realidades, y como tales, factores reales que ejercían a su vez una acción deformante" (2008, p. 212); de este modo la ideología en la sociedad descrita por este autor francés tiene un papel deformador de la realidad, en la cual es la imagen producto del espectáculo una de las bases para producir la alienación.

Por otra parte, desde la óptica marxista "la ideología impregna todas las actividades del hombre comprendiendo entre ellas la práctica económica y la práctica política" (Harnecker, 1970, 69). Con base en esto se puede afirmar que la Constitución se encuentra permeada por la ideología de la clase dominante, y por la estructura económica. Es de tener en cuenta que el texto constitucional pertenece a la superestructura, y permite perpetuar la dominación de una clase social por otra; lo interesante es ver cómo la ideología que es un "conocimiento necesariamente deformado y falseado" (Harnecker, 1970, p. 78) que sirve de asidero a la Constitución tiene un doble uso: "Se ejerce sobre la conciencia de los explotados para hacerles aceptar como natural su condición de explotados; se ejerce sobre los miembros de la clase dominante para permitirles ejercer como natural su explotación y dominación" (Harnecker, 1970, p. 72). Para la perspectiva en la cual se aborda el presente tema, se debe rescatar entonces que, si el texto constitucional es producto de una ideología deformadora, necesariamente la interpretación, que se realiza acerca del mismo por los diversos funcionarios que sirven al Estado como agente de explotación, es una manera de perpetuar la dominación de la clase social dominante, es decir, una interpretación que conserva la distorsión. En otras palabras, desde este punto de vista es evidente que una Constitución participa de la función de la ideología, al ser el producto de una clase social dominante que impone el texto y lo hace pasar como los intereses de todo un pueblo para obtener legitimidad a través del disimulo. Así, la interpretación de un texto deformador es, de suyo, deformada, y, por ende, será patológica.

Lo anterior es acertado desde la óptica marxista, y no se pretende ni refutar ni aceptar de plano el marxismo; lo que se quiere mostrar es cómo por fuera del marxismo la ideología como deformación se encuentra presente; se puede pensar en un texto constitucional en el cual están presentes las dos primeras funciones, es decir, es ideológicamente integrador y legitimador, pero en el cual su interpretación puede devenir distorsionadora. Acá cabe preguntarse: ¿Una interpretación constitucional en la cual esté presente esta función disimuladora puede llevar a mutar el texto constitucional? La respuesta debe ser afirmativa, porque el texto constitucional cobra sentido por medio de los significados otorgados por sus intérpretes autorizados, y si estos le dan un significado diferente para imponer una determinada ideología estarían generando una imagen deformada del texto constitucional. Por ello se suscribe la siguiente idea: 
La mutación constitucional no tiene cabida en la Teoría de la Constitución como categoría alternativa a la reforma, aun con limitaciones, sino como mera descripción de un fenómeno siempre patológico que se produce cuando la reformulación semántica de normas constitucionales desborda los criterios y cánones de la interpretación constitucional y, sin embargo, la jurisdicción constitucional permite su consolidación actuando ella misma como poder constituyente o plegándose, por acción u omisión, ante dinámicas «constituyentes» que discurren al margen del procedimiento de reforma. (Rollnert, 2014, p. 152)

Aunque el autor no habla expresamente de la ideología la expresión de "fenómeno siempre patológico" tiene resonancias con la función de la ideología como distorsión o disimulo, pues la misma también es patológica. La mutación constitucional, en el sentido negativo que acá se menciona, es en últimas el reflejo de una ideología presente en la jurisdicción constitucional la cual la lleva de un modo u otro a asumir un poder constituyente otorgando significados distintos con base en una reformulación semántica basada en una ideología de fondo que distorsiona a aquella que dio pie a la Constitución y sirvió de base para legitimar e integrar. Ahora bien, es de relievar que la mutación de la Constitución es patológica cuando ella da una imagen de una continuidad constitucional cuando en el fondo está ocultando una ideología que se está imponiendo por parte de los intérpretes constitucionales.
Por otra parte, la función de distorsión puede presentarse de varias maneras:

(i) cuando un Tribunal constitucional tiene estrechas relaciones con el órgano ejecutivo, donde las interpretaciones ya no buscan tanto la legitimación del sistema, sino dar una apariencia de constitucionalidad a las actuaciones del otro órgano. Acá cabe mencionar que según "el enfoque 'actor estratégico', que considera a los jueces como actores políticos ambiciosos que emiten fallos guiados por las oportunidades y limitaciones del sistema político dentro del cual operan" Kapiszewski, 2006, p. 7), si para ellos es más conveniente hacer prevalecer una ideología deformadora para alcanzar sus intereses, lo harán. A modo de ejemplo,

\begin{abstract}
En su estudio sobre la jurisprudencia de la Corte Suprema, argentina y chilena, desde la década del cuarenta a la década del noventa, Scribner (2004) establece que la predisposición de los jueces a cuestionar las decisiones adoptadas por la autoridad presidencial dependió en gran medida de la relación que los ministros tenían con el presidente (en términos de haber sido designados por él o no), y de la probabilidad de que los jueces pudieran enfrentar mayorías coherentes o represalias políticas. (Kapiszewski, 2006, p. 7)
\end{abstract}

(ii) cuando la ideología de los intérpretes de manera velada se pone por encima del texto constitucional, distorsionando los significados del mismo para 
hacer prevalecer ciertas posiciones ideológicas, se hace pasar por interpretación jurídica una deformación, es decir, sobre lo que debería ser se coloca una imagen falsa. Se ha dicho que

[...] los jueces siempre 'niegan' en el sentido común del término, que estén actuando por motivos ideológicos. Esto es, afirman expresamente que el resultado [...] fue alcanzado siguiendo procedimientos interpretativos impersonales que excluyen la influencia de sus ideologías personales. (Kennedy, 2010, p. 36)

Y aunque no se puede probar que los jueces 'siempre' nieguen el uso de la ideología, es claro que existe la posibilidad de que ellos otorguen significado a los textos constitucionales con base en alguna ideología diferente a la del texto constitucional, logrando que otra ideología vaya deformando la ideología integradora y legitimadora de base.

\section{CONCLUSIONES}

La presencia de la ideología en la interpretación de la Constitución es inevitable. Por lo cual, es importante distinguir las diversas formas de funcionar de la ideología, pues a partir de esta distinción se puede comprender de una manera acertada qué hacen los intérpretes del texto constitucional a partir de la ideología. En este orden de ideas, el presente artículo es una invitación a distinguir las funciones de la ideología en la interpretación de la Constitución y a la realización de investigaciones en las cuales se estudien sentencias de los diversos tribunales constitucionales y se determine de qué manera se está utilizando la ideología, para fortalecer la democracia.

Definir hermenéutica constitucional no es una operación ideológicamente neutra; establecer si es solo determinar sentido o incluir la actividad de valoración por parte del intérprete constitucional muestra la imagen que se tiene de la actividad del intérprete y de los resultados esperados de la interpretación.

Aceptar que los fenómenos culturales llevan a interpretar el texto constitucional conlleva admitir que la Constitución está permeada por la ideología, pues los significados otorgados al texto constitucional dependen de los contextos ideológicos que lentamente se van sedimentando en los miembros de una comunidad. Además, adoptar el sentido amplio, frente a los intérpretes constitucionales, es un intento por incluir diversas visiones ideológicas provenientes de la ciudadanía y de diversos grupos en la interpretación de la Constitución, haciendo de ella un texto lleno de ecos ideológicos no capturados por uno o varios intérpretes legítimos.

Escoger la postura originalista de la interpretación constitucional es ser ideológicamente conservador, y busca mantener unos determinados valores a lo largo del tiempo, sometiendo a los individuos a la ideología original de la Constitución. Por otra parte, elegir la postura del activismo judicial implica una mirada sociológica en la cual se busca actualizar el texto 
constitucional, corriendo el riesgo de borrar tradiciones históricas, y de derivar en posturas ideológicas amañadas ya que mucho depende del 'sentimiento de justicia'.

Temer por sí misma a la ideología en la interpretación constitucional resulta de desconocer los diferentes usos que puede tener la ideología en una sociedad y, por ende, los usos que puede tener en la interpretación constitucional. Con base en Ricoeur se concluye que la ideología en la hermenéutica constitucional puede funcionar integrando, legitimando o distorsionando. Por ello quienes ejercen la interpretación constitucional, independiente que sea en sentido amplio o restringido, deben velar por el correcto uso de la ideología en la interpretación de la Constitución; en un Estado social constitucional y democrático de derecho la ideología en la hermenéutica constitucional debe mantenerse en unos grados óptimos de realización, es decir, que integre a la comunidad y no la divida, que legitime el ejercicio de poder democrático y que excluya en la medida de lo posible la distorsión o disimulo para no continuar generándole imágenes distorsionadas a la sociedad civil.

\section{REFERENCIAS}

Arteaga, E. (2005). La interpretación constitucional. En E. Ferrer Mac-Gregor (Ed.), Interpretación constitucional Tomo I (pp. 61-120). México D. F., México: Universidad Nacional Autónoma de México y Editorial Porrúa.

Asís, R. (2008). Sobre la interpretación de la constitución. En Ferrer Mac-Gregor, E. y Zaldívar Lelo de Larrea, A. (Ed.), La ciencia del derecho procesal constitucional. Estudios en homenaje a Héctor Fix-Zamudio en sus cincuenta años como investigador del derecho, Tomo VI, Interpretación constitucional y jurisdicción electoral (pp. 211-230). México D. F., México: Instituto de Investigaciones Jurídicas UNAM.

Bocanument, M., Restrepo, O. y Rojas, M. (2015). Tipos y modalidades de participación en el proceso político constituyente de 19901991 en Colombia. En M. Bocanument, O. Restrepo y M. Rojas (Eds.), Participación ciudadana en el proceso constituyente de 1991 (pp. 148-245). Medellín, Colombia: Sello Editorial Universidad de Medellín, Fondo Editorial Remington y Colciencias.

Burgoa, I. (2005). Interpretación constitucional. En E. Ferrer Mac-Gregor (Ed.), Interpretación constitucional Tomo I (pp. 227-235). México D. F., México: Universidad Nacional Autónoma de México y Editorial Porrúa.

Carbonell, M. (2012). Sobre la Constitución viviente. Revista Facultad de Derecho y Ciencias Políticas, 42(117), 347-357.

Carmona, J. (2005). Algunos aspectos sobresalientes de la interpretación judicial. En E. Ferrer Mac-Gregor (Ed.), Interpretación constitucional Tomo I (pp. 281-319). México D. F., México: Universidad Nacional Autónoma de México y Editorial Porrúa.

Carpizo, J. y Fix-Zamudio, H. (2005). Algunas reflexiones sobre la interpretación constitucional. En E. Ferrer Mac-Gregor (Ed.), Interpretación constitucional Tomo I (pp. 385-438). México D. F., México: Universidad Nacional Autónoma de México y Editorial Porrúa.

Debord, G. (2008). La sociedad del espectáculo. Buenos Aires, Argentina: La Marca Editora.

Eagleton, T. (1997). Ideología. Barcelona, España: Paidós.

Fix-Zamudio, H. (2008). Lineamientos esenciales de la interpretación constitucional. En E. Ferrer Mac-Gregor (Ed.), Interpretación 
constitucional Tomo I (pp. 521-575). México D. F., México Universidad Nacional Autónoma de México y Editorial Porrúa.

Guastini. R. (1997). Problemas de interpretación. Isonomía, (7), 121-137.

Guastini, R. (2008). Teoría e ideología de la interpretación constitucional. Madrid, España: Trotta.

Grondin, J. (2008). ¿Qué es la hermenéutica? Barcelona, España: Herder.

Háberle, P. (2002). La Constitución como cultura. Bogotá, Colombia: Universidad Externado de Colombia.

Harnecker, M. (1970). Los conceptos elementales del materialismo histórico. México D. F., México: Siglo Veintiuno.

Hesse, K. (2011). Escritos de Derecho constitucional. Madrid, España: Centro de Estudios Políticos y Constitucionales.

Higton, H. (2010). Sistemas concentrado y difuso de control de Constitucionalidad. En Bogdandy, A., Ferrer Mac-Gregor, E. y Morales Antoniazzi, M. (Ed.), La justicia constitucional y su internacionalización. ¿Hacia una ius constitutionale commune en América Latina?, Tomo I (pp. 107-173). México D.F., México: Instituto de Investigaciones Jurídicas, Max-Planck-Institut Für Ausländisches Öffentliches Recht und Völkerrecht e Instituto Iberoamericano de Derecho Constitucional.

Huerta, C. (2008). Interpretación Constitucional. En E. Ferrer Mac-Gregor y Zaldívar Lelo de Larrea, A. (Ed.), La ciencia del derecho procesal constitucional. Estudios en homenaje a Héctor FixZamudio en sus cincuenta años como investigador del derecho, Tomo VI, Interpretación constitucional y jurisdicción electoral. (pp. 281-323). México D. F., México: Instituto de Investigaciones Jurídicas UNAM.
Kapiszewski, D. (2006). La Corte Suprema y la política constitucional en la Argentina Post-Menem. Revista jurídica de la Universidad de Palermo, 7(1) 5-46.

Kennedy, D. (2010). Izquierda y derecho. Ensayos de teoría jurídica crítica. Buenos Aires, Argentina: Siglo Veintiuno.

Loewenstein, K. (1982). Teoría de la Constitución. Barcelona, España: Ariel.

Rawls, J. (1995). Teoría de la justicia. México D.F., México: Fondo de Cultura Económica.

Ricoeur, P. (2004). Del texto a la acción. Ensayos de hermenéutica II. (Trad). Pablo Corona. México D. F., México: Fondo de Cultura Económica.

Ricoeur, P. (2008a). El conflicto de las interpretaciones. Ensayos de hermenéutica. Buenos Aires, Argentina: Fondo de Cultura Económica.

Ricoeur, P. (2008b). Ideología y utopía. (Trad). Alcira Bixio. Barcelona, España: Gedisa.

Ricoeur, P. (2008c). Lo justo 2. Madrid, España: Trotta.

Robles, G. (2012). El pensamiento jurídico de Hans Kelsen: una lectura crítica de la teoría pura del derecho. En A. Botero Bernal (Ed.), Filosofía del Derecho (pp. 223-285). Medellín, Colombia: Sello Editorial Universidad de Medellín.

Rollnert, G. (2014). La mutación constitucional, entre la interpretación y la jurisdicción constitucional. Revista Española de Derecho Constitucional, (101), 125-155.

Ross, A. (1977). Sobre el derecho y la justicia. Buenos Aires, Argentina: Eudeba.

Weber, M. (2005). Economía y sociedad. México D.F, México: Fondo de Cultura Económica. 